\title{
RESEARCH \\ Identification of the Complete Coding Sequence and Genomic Organization of the Treacher Collins Syndrome Gene
}

\author{
Jill Dixon, ${ }^{1}$ Sara J. Edwards, ${ }^{1}$ Isobel Anderson, ${ }^{2}$ Andrew Brass, ${ }^{2}$ \\ Peter J. Scambler, ${ }^{3}$ and Michael J. Dixon ${ }^{1,4}$ \\ ${ }^{1}$ School of Biological Sciences and Departments of Dental Medicine and Surgery, and ${ }^{2}$ School of Biological \\ Sciences, University of Manchester, Manchester M13 9PT, UK; ${ }^{3}$ Molecular Medicine Unit, Institute of Child \\ Health, London WC1N 1EH, UK
}

Treacher Collins syndrome (TCS) is an autosomal dominant disorder of craniofacial development, the features of which include conductive hearing loss and cleft palate. Recently, the demonstration of a series of 10 mutations within a partial-length CDNA clone have indicated that the TCS gene (TCOFI) has been positionally cloned. Although it has been shown that the gene is expressed in a wide variety of fetal and adult tissues, database sequence comparisons have failed to provide significant information on the function of the gene. In the current investigation, a combination of CDNA library screening and rapid amplification of CDNA ends has permitted the isolation of the complete coding sequence of TCOFI, which is encoded by 26 exons and predicts a low complexity, serine/alanine-rich protein of $\sim 144 \mathrm{kD}$. The use of a variety of bioinformatics tools has resulted in the identification of repeated units within the gene, each of which maps onto an individual exon. The predicted protein Treacle contains numerous potential phosphorylation sites, a number of which map to similar positions within the repeated units, and shows weak but significant homology to the nucleolar phosphoproteins. Although the precise function of Treacle remains unknown, these observations suggest that phosphorylation may be important for its role in early embryonic development and that it may play a role in nucleolar-cytoplasmic shuttling. The information presented in this study will allow continued mutation analysis in families with a history of TCS and should facilitate continued experimentation to shed further light on the function of the gene/protein during development of the craniofacial complex.

[The sequence data described in this paper have been submitted to the GenBank data library under accession nos. U40847 and U79645-U79660.]

Treacher Collins syndrome (TCS) is an autosomal dominant disorder of facial development, which was probably first reported by Thompson (1846), but is named after E. Treacher Collins, who described the essential features of the syndrome in 1900 (Treacher Collins 1900). The incidence of TCS is thought to be $\sim 1 / 50,000$ live births (Fazen et al. 1967; Gorlin et al. 1990), with $60 \%$ of cases appearing to arise as the result of a de novo mutation (Jones et al. 1975). TCS displays high penetrance, with only one reported case of nonpenetrance (Dixon et al. 1994a) and a high degree of both interand intrafamilial phenotypic variability. The clinical manifestations include the following. (1) Abnormalities of the external ears, which are frequently

${ }^{4}$ Corresponding author.

E-MAlL mdixon@fs2.scg.man.ac.uk; FAX + 44-161 2755620. associated with narrowing of the ear canals and abnormalities of the middle-ear ossicles. Bilateral conductive hearing loss is therefore a common feature of this disorder (Phelps et al. 1981). (2) Hypoplasia of the facial bones, particularly the mandible and zygomatic complex. (3) Downward slanting of the palpebral fissures with colobomas (notching) of the lower eyelids and a lack of eyelashes medial to the defect. (4) Cleft palate. These features are usually bilaterally symmetrical (Kay and Kay 1989); however, because of the variability in expression, it can be extremely difficult to reach a clinical diagnosis and to provide accurate genetic counselling.

The Treacher Collins syndrome locus (TCOF1) was initially linked to polymorphic markers from chromosome 5 at 5q31-34 (Dixon et al. 1991). This localization was subsequently confirmed by Jabs et al. (1991), and more recent studies have resulted in 


\section{DIXON ET AL.}

the creation of a combined genetic and radiation hybrid map around the TCOF1 locus (Dixon et al. 1993; Loftus et al. 1993). This map allowed a yeast artificial chromosome (YAC) contig of the region to be constructed (Jabs et al. 1993; Dixon et al. 1994b). Transcription mapping of the TCOF1 candidate region eventually led to the identification of a cDNA clone with an open reading frame (ORF) of $4142 \mathrm{bp}$ that did not contain a translation initiation signal, a polyadenylation signal, or a poly(A) tail (Loftus et al. 1996; Treacher Collins Syndrome Collaborative Group 1996). Investigation of this cDNA led to the identification of different mutations in 10 unrelated families, all of which resulted in the introduction of a premature termination codon into the predicted protein product, Treacle (Gladwin et al. 1996; Treacher Collins Syndrome Collaborative Group 1996).

As the structures affected in TCS arise from the first and second pharyngeal arches, which in turn have a significant contribution from the neural crest, it has been proposed that the disorder may be the result of a defect in neural crest cell migration or improper cellular differentiation during development (Poswillo 1975; Wiley et al. 1983). The identification of the TCOF1 gene has, however, failed to elucidate the biochemical nature of the disorder as initial database comparisons have indicated that it has no strong homologies with previously identified genes, gene families, or protein motifs of classic importance. In this study we report the complete sequence of TCOF1 and its genomic organization, which has allowed us to identify repeated units within the gene that map onto individual exons. Analysis of TCOF1/Treacle using a number of bioinformatics tools has suggested further that protein phosphorylation may be important for its function.

\section{RESULTS}

\section{Isolation of the Entire Coding Sequence of TCOF1}

Screening of a number of cDNA libraries with portions of the original cDNA clone (Treacher Collins Syndrome Collaborative Group 1996) failed to identify any clones that extended the sequence previously presented in a $3^{\prime}$ direction. Extension of the sequence of the TCOF1 gene in this direction was therefore achieved using rapid amplification of cDNA ends (RACE). Sequence analysis of a 3' RACE product of $\sim 600 \mathrm{bp}$ isolated using this methodology revealed that it extended the cDNA sequence presented previously by $565 \mathrm{bp}$, including an additional $40 \mathrm{bp}$ of coding sequence prior to the first in-frame termination codon. Initial screening of cDNA libraries also failed to identify a clone that extended the sequence in a $5^{\prime}$ direction. $5^{\prime}$ RACE produced two PCR products, the smaller of which did not extend the previously reported cDNA sequence. Sequencing of the larger product resulted in the identification of an additional $69 \mathrm{bp}$ of sequence, including a strong Kozak consensus initiation sequence (Kozak 1987a,b). Screening of a human fetal brain cDNA library with the larger of the 5' RACE products identified three cDNA clones, all of which provided additional sequence information. The longest of these clones contained the start codon and an in-frame termination codon (TAA) 75 bp upstream. RT-PCR analysis of the 5' end of the gene flanking the initiation codon using RNA extracted from skeletal muscle and a lymphoblastoid cell line yielded a single PCR product of the predicted size, the sequence of which was in perfect agreement with that of the cDNA clone. The combined cDNA cloning and RACE strategies have therefore resulted in the identification of the complete coding sequence of TCOF1, which consists of an ORF of $4233 \mathrm{bp}$, followed by a termination codon and a 3' untranslated region (UTR) of 507 bp, which contains a single polyadenylation signal. A 5' UTR of $93 \mathrm{bp}$ has also been identified (Fig. 1). This sequence predicts a $144-\mathrm{kD}$ protein of 1411 amino acids (Fig. 1). The predicted protein is of low complexity with 5 amino acids, alanine (14.86\%), serine $(13.59 \%)$, lysine $(11.18 \%)$, glutamic acid $(9.13 \%)$, and proline $(9.06 \%)$, accounting for the majority of residues.

\section{Genomic Organization of the Gene}

Experiments aimed at determining the genomic organization of TCOF1 indicated that the gene is encoded by 26 exons, ranging in size from 49 to 561 bp (Table 1). Exon 1 contains the translation initiation signal, preceded by the 5' UTR, which contains a large number of rare-cutter restriction sites, including two BssHII, two FseI, and two EagI sites, within $93 \mathrm{bp}$. Exon 25 contains the last $24 \mathrm{bp}$ of the coding sequence, the termination codon, and the first $22 \mathrm{bp}$ of the 3' UTR. The remainder of the 3' UTR is encoded by exon 26. The intron/exon boundary sequences conform to the published consensus sequences (Table 1) (Breathnach and Chambon 1981), with the exception of exon 14, the splice donor site of which displays the sequence GC rather than the more usual GT. The intron/exon boundaries are of type 0 (splicing occurring between codons) for introns $1,4,6-16,18,19,21$, and 24; 


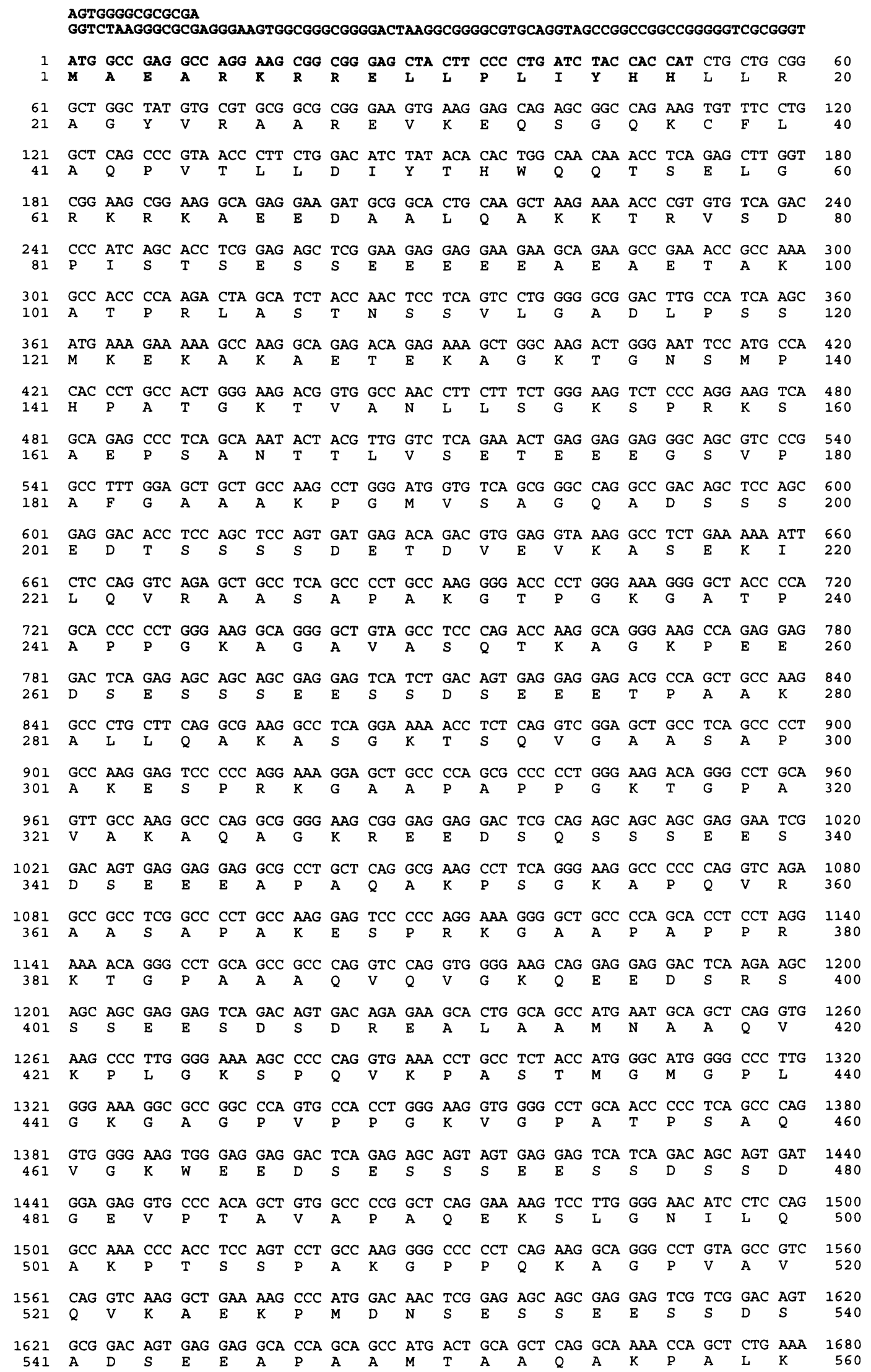

Figure 1 (See p. 227 for legend.) 
DIXON ET AL.

1681 ATT CCT CAG ACC AAG GCC TGC CCA AAG AAA ACC AAT ACC ACT GCA TCT GCC AAG GTC GCC 1740

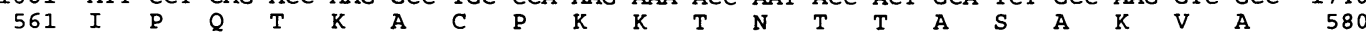

1741 CCT GTG CGA GTG GGC ACC CAA CCC CCC CGG AAA GCA GGA ACT GCG ACT TCT CCA GCA GGC 1800

$\begin{array}{llllllllllllllllllllll}581 & \text { P } & \text { V } & \text { R } & \text { V } & \text { G } & \text { T } & \text { Q } & \text { P } & \text { P } & \text { R } & \text { K } & \text { A } & \text { G } & \text { T } & \text { A } & \text { T } & \text { S } & \text { P } & \text { A } & \text { G } & 600\end{array}$

1801 TCA TCC CCA GCT GTG GCT GGG GGC ACC CAG AGA CCA GCA GAG GAT TCT TCA AGC AGT GAG 1860

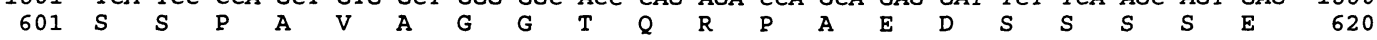

1861 GAA TCA GAT AGT GAg GAA GAg AAg ACA GGT CTT GCA GTA ACC GTG GGA CAg GCA AAG TCT 1920

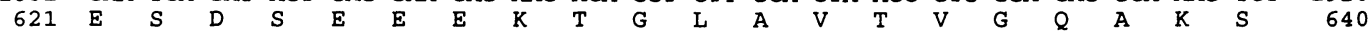

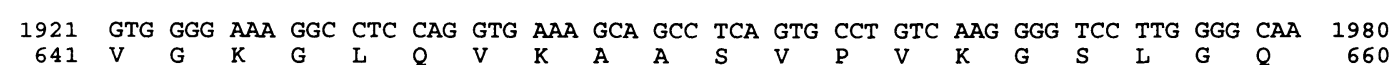

1981 GGG ACT GCT CCA GTA CTC CCT GGG AAG ACG GGG CCT ACA GTC ACC CAG GTG AAA GCT GAA 2040

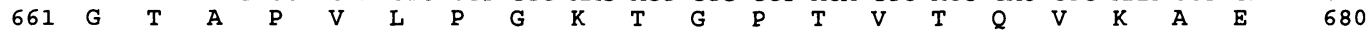

2041 AAG CAG GAA GAC TCT GAG AGC AGT GAG GAG GAA TCA GAC AGT GAG GAA GCA GCT GCA TCT 2100

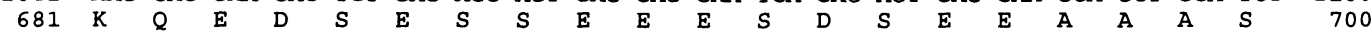

2101 CCA GCA CAG GTG AAA ACC TCA GTA AAG AAA ACC CAG GCC AAA GCC AAC CCA GCT GCC GCC 2160

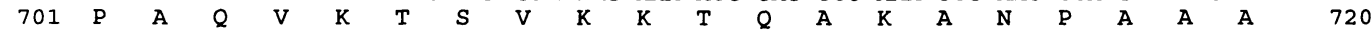

2161 AGA GCA CCT TCA GCA AAA GGG ACA ATT TCA GCC CCT GGA AAA GTT GTC ACT GCA GCT GCT 2220

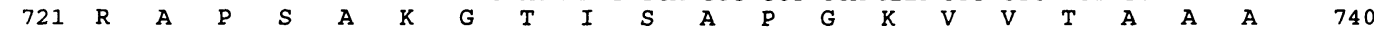

2221 CAA GCC AAG CAG AGG TCT CCA TCC AAG GTG AAG CCA CCA GTG AGA AAC CCC CAG AAC AGT 2280

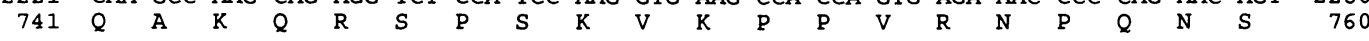

2281 ACC GTC TTG GCG AGG GGC CCA GCA TCT GTG CCA TCT GTG GGG AAG GCC GTG GCT ACA GCA 2340

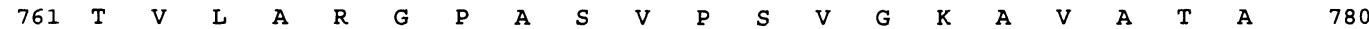

2341 GCT CAG GCC CAG ACA GGG CCA GAG GAG GAC TCA GGG AGC AGT GAG GAg GAG TCA GAC AGT 2400

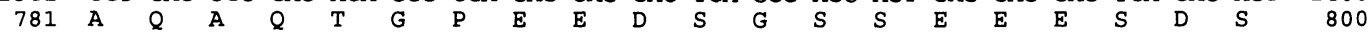

2401 GAG GAG GAG GCG GAG ACG CTG GCT CAG GCG AAG CCT TCA GGG AAG ACC CAC CAG ATC AGA 2460

$\begin{array}{llllllllllllllllllllll}801 & E & E & E & A & E & T & \text { L } & \text { A } & \text { Q } & \text { A } & \text { K } & \text { P } & \text { S } & \text { G } & \text { K } & \text { T } & \text { H } & \text { Q } & \text { I } & R & 820\end{array}$

2461 GCT GCC TTG GCT CCT GCC AAG GAG TCC CCC AGG AAA GGG GCT GCC CCA ACA CCT CCT GGG 2520

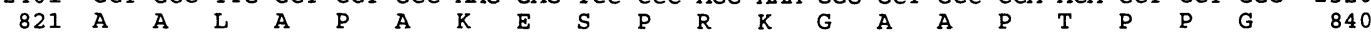

2521 AAG ACA GGG CCT TCG GCT GCC CAG GCA GGG AAG CAG GAT GAC TCA GGg AGC AGC AGC GAG 2580

$\begin{array}{llllllllllllllllllllll}841 & K & \text { T } & \text { G } & \text { P } & \text { S } & \text { A } & \text { A } & \text { Q } & \text { A } & \text { G } & \text { K } & \text { Q } & \text { D } & \text { D } & S & \text { G } & S & S & S & E & 860\end{array}$

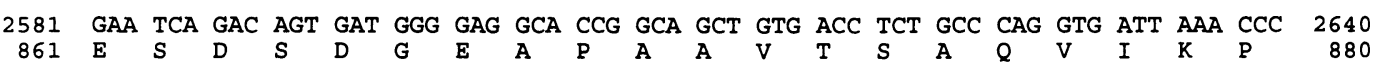

2641 CCC CTG ATT TTT GTC GAC CCT AAT CGT AGT CCA GCT GGC CCA GCT GCT ACA CCC GCA CAA 2700

\begin{tabular}{llllllllllllllllllllll}
881 & P & L & I & F & V & D & P & N & R & S & P & A & G & P & A & A & T & P & A & $Q$ & \\
\hline
\end{tabular}

2701 GCC CAG GCT GCA AGC ACC CCG AGG AAG GCC CGA GCC TCG GAG AGC ACA GCC AGG AGC TCC 2760

$\begin{array}{llllllllllllllllllllll}901 & A & Q & A & A & S & T & P & R & K & A & R & A & S & E & S & T & A & R & S & S & 920\end{array}$

2761 TCC TCC GAG AGC GAG GAT GAG GAC GTG ATC CCC GCT ACA CAA TGC TTG ACT CCT GGC ATC 2820

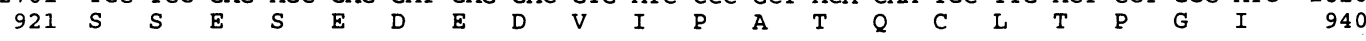

2821 AGA ACC AAT GTG GTG ACC ATG CCC ACT GCC CAC CCA AGA ATA GCC CCC AAA GCC AGC ATG 2880

$\begin{array}{llllllllllllllllllllll}941 & R & T & N & V & V & T & M & P & T & A & H & P & R & I & A & P & K & A & S & M & 960\end{array}$

2881 GCT GGG GCC AGC AGC AGC AAG GAG TCC AGT CGG ATA TCA GAT GGC AAG AAA CAG GAG GGA 2940

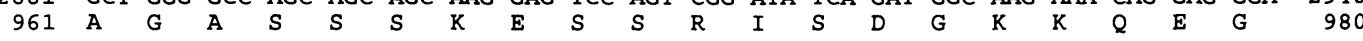

2941 CCA GCC ACT CAG GTG TCA AAG AAG AAC CCA GCT TCC CTC CCA CTG ACC CAG GCT GCC CTG 3000

$\begin{array}{lllllllllllllllllllllll}981 & \mathrm{P} & \mathrm{A} & \mathrm{T} & \mathrm{Q} & \mathrm{V} & \mathrm{S} & \mathrm{K} & \mathrm{K} & \mathrm{N} & \mathrm{P} & \mathrm{A} & \mathrm{S} & \mathrm{L} & \mathrm{P} & \mathrm{L} & \mathrm{T} & \mathrm{Q} & \mathrm{A} & \mathrm{A} & \mathrm{L} & 1000\end{array}$

3001 AAG GTC CTC GCC CAG AAA GCC AGT GAG GCT CAG CCT CCT GTT GCC AGG ACC CAG CCT TCA 3060

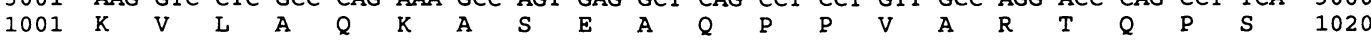

3061 AGT GGG GTT GAC AGT GCT GTG GGA ACA CTC CCT GCA ACA AGT CCC CAg AGC ACC TCC GTC 3120

$\begin{array}{llllllllllllllllllllll}1021 & S & G & V & D & S & A & V & G & T & \text { L } & \text { P } & \text { A } & \text { T } & \text { S } & \text { P } & \text { Q } & \text { S } & \text { T } & S & \text { V } & 1040\end{array}$

3121 CAG GCC AAA GGG ACC AAC AAG CTC AGA AAA CCT AAG CTT CCT GAG GTC CAG CAG GCC ACC 3180

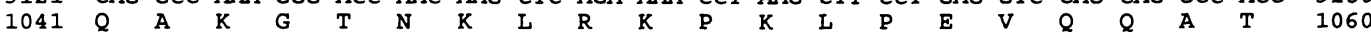

3181 AAA GCC CCT GAG AGC TCA GAT GAC AGT GAG GAC AGC AGC GAC AGT TCT TCA GGG AGT GAG 3240

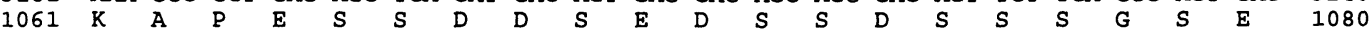

3241 GAA GAT GGT GAA GGG CCC CAG GGG GCC AAG TCA GCC CAC ACG CTG GGT CCC ACC CCC TCC 3300

$\begin{array}{llllllllllllllllllllll}1081 & \text { E } & \text { D } & \text { G } & \text { E } & \text { G } & \text { P } & \text { Q } & \text { G } & \text { A } & \text { K } & \text { S } & \text { A } & \text { H } & \text { T } & \text { L } & \text { G } & \text { P } & \text { T } & \text { P } & \text { S } & 1100\end{array}$

3301 AGG ACA GAG ACC CTG GTG GAg GAG ACC GCA GCA GAG TCC AGC GAg GAT GAT GTG GTG GCG 3360

$\begin{array}{llllllllllllllllllllll}1101 & R & T & E & T & L & V & E & E & T & A & A & E & S & S & E & D & D & V & V & A & 1120\end{array}$

3361 CCA TCC CAG TCT CTC CTC TCA GGT TAT ATG ACC CCT GGA CTA ACC CCA GCC AAT TCC CAG 3420

$\begin{array}{llllllllllllllllllllll}1121 & P & S & Q & S & L & L & S & G & Y & M & T & P & G & L & T & P & A & N & S & O & 1140\end{array}$

Figure 1 (Continued) 
type 1 (splicing occurring after the first base of the codon) for introns $3,5,17,20,22$, and 23; and type 2 (splicing occurring after the second base of the codon) for intron 2 . In many cases, the introns were sequenced in their entirety, which permitted their sizes to be determined accurately, whereas the sizes of other introns were estimated by PCR (Table 1). Interestingly, sequence analysis of the 3' UTR indicated that it was not single exonic, an intron of $\sim 730 \mathrm{bp}$, as determined by the PCR, being present between exons 25 and 26. Introns $1,3,6,13$, and 16 consistently could not be amplified using PCR, and thus these introns were considered to be out of the range of PCR amplification under the conditions used in this study. The entire sequence data generated in this study have been submitted to GenBank under the following accession numbers: U79645 (exon 1); U79646 (exon 2); U79647 (exon 3);
U79648 (exon 4); U79649 (exon 5); U79650 (exon 6); U79651 (exon 7 to exon 13); U79652 (exon 14 to exon 16); U79653 (exon 17); U79654 (exon 18); U79655 (exons 19 and 20); U79656 (exon 21); U79657 (exon 22); U79658 (exon 23); U79659 (exons 24 and 25); and U79660 (exon 26). All available intronic sequence has been submitted under the appropriate accession number.

\section{Bioinformatics Analysis}

As initial database sequence comparisons failed to show any strong homologies between TCOF1 and previously identified genes, gene families, or motifs of classic importance, a number of bioinformatics programs were employed in the current study. The use of dot plots allowed the identification of repeated units within the gene, each of which was

\begin{tabular}{|c|c|c|c|c|c|c|c|c|c|c|c|c|c|c|c|c|c|c|c|c|c|}
\hline & $\mathrm{CC}$ & $\begin{array}{l}\text { TCA } \\
\mathrm{S}\end{array}$ & $\begin{array}{l}\text { AAA } \\
\mathrm{K}\end{array}$ & $\begin{array}{l}\text { GCC } \\
\text { A }\end{array}$ & $\begin{array}{l}\text { ACT } \\
T\end{array}$ & $\begin{array}{l}\mathrm{CCC} \\
\mathrm{P}\end{array}$ & $\begin{array}{l}\text { AAG } \\
\mathrm{K}\end{array}$ & $\begin{array}{l}\text { CTA } \\
\mathrm{L}\end{array}$ & $\begin{array}{l}\text { GAT } \\
\text { D }\end{array}$ & $\begin{array}{l}\text { TCC } \\
\mathrm{S}\end{array}$ & $\begin{array}{l}\text { AGC } \\
S\end{array}$ & $\begin{array}{l}\text { CCC } \\
P\end{array}$ & $\begin{array}{l}\text { TCA } \\
S\end{array}$ & $\begin{array}{l}\text { GTT } \\
\text { V }\end{array}$ & $\begin{array}{l}\text { TCC } \\
S\end{array}$ & $\begin{array}{l}\text { TCT } \\
\mathrm{S}\end{array}$ & $\begin{array}{l}\mathrm{ACT} \\
\mathrm{T}\end{array}$ & $\begin{array}{l}\text { CTG } \\
\text { L }\end{array}$ & $\begin{array}{l}\text { GCC } \\
\text { A }\end{array}$ & $\begin{array}{l}\text { GCC } \\
\text { A }\end{array}$ & $\begin{array}{l}3480 \\
1160\end{array}$ \\
\hline & $A A$ & $\begin{array}{l}\text { GAT } \\
\mathrm{D}\end{array}$ & $\begin{array}{l}\text { GAC } \\
\text { D }\end{array}$ & $\begin{array}{l}\mathrm{CCA} \\
\mathrm{p}\end{array}$ & GAT & $\begin{array}{l}\text { GGC } \\
\text { G }\end{array}$ & $\begin{array}{l}\text { AAG } \\
\mathrm{K}\end{array}$ & $A G$ & AG & $\begin{array}{l}\text { GCA } \\
\text { A }\end{array}$ & $\begin{array}{l}\text { AAG } \\
\mathrm{K}\end{array}$ & $\mathrm{CC}$ & $\begin{array}{l}\text { CAA } \\
Q\end{array}$ & $\begin{array}{l}\text { CAG } \\
Q\end{array}$ & $\begin{array}{l}\text { GCA } \\
\text { A }\end{array}$ & $\begin{array}{l}\text { GCA } \\
\text { A }\end{array}$ & GC & $\begin{array}{l}\text { ATG } \\
M\end{array}$ & $\begin{array}{l}\text { TTG } \\
\mathrm{L}\end{array}$ & $\mathrm{CC}$ & \\
\hline & $\mathrm{CT}$ & $\begin{array}{l}\text { AAA } \\
K\end{array}$ & $\begin{array}{l}\mathrm{ACA} \\
\mathrm{T}\end{array}$ & $\begin{array}{l}\text { GGT } \\
\text { G }\end{array}$ & GGA & $\begin{array}{l}\text { AAA } \\
K\end{array}$ & $\begin{array}{l}\text { GAG } \\
\mathrm{E}\end{array}$ & $\mathrm{CT}$ & GCT & $\begin{array}{l}\text { TCA } \\
\mathrm{S}\end{array}$ & GGC & $\mathrm{CC}$ & $\mathrm{ACA}$ & $\begin{array}{l}\mathrm{CCT} \\
\mathrm{P}\end{array}$ & AG & AAG & $\begin{array}{l}\text { TCC } \\
S\end{array}$ & $\begin{array}{l}\text { CGG } \\
R\end{array}$ & AAG & CCC & $\begin{array}{l}00 \\
00\end{array}$ \\
\hline & AG & AA & $\begin{array}{l}\text { GGG } \\
\text { G }\end{array}$ & $\begin{array}{l}\text { GCT } \\
\text { A }\end{array}$ & $\begin{array}{l}\text { GGG } \\
\text { G }\end{array}$ & AC & $\begin{array}{l}\mathrm{CCC} \\
\mathrm{P}\end{array}$ & AA & $\mathrm{CC}$ & $\begin{array}{l}\text { TCA } \\
S\end{array}$ & $\begin{array}{l}\mathrm{ACC} \\
\mathrm{T}\end{array}$ & TG & $\begin{array}{l}\text { GCG } \\
\text { A }\end{array}$ & $\begin{array}{l}\text { CTG } \\
\text { L }\end{array}$ & $2 A A$ & $\begin{array}{l}\text { AGC } \\
\mathrm{S}\end{array}$ & $\begin{array}{l}\text { AAC } \\
\mathrm{N}\end{array}$ & $\begin{array}{l}\text { ATC } \\
\text { I }\end{array}$ & ACC & CAG & \\
\hline & GC & $\begin{array}{l}\text { CTC } \\
\mathrm{L}\end{array}$ & $\begin{array}{l}\text { CTG } \\
\mathrm{L}\end{array}$ & $\begin{array}{l}\text { GGC } \\
\text { G }\end{array}$ & $\begin{array}{l}\text { CAA } \\
Q\end{array}$ & $\mathrm{CC}$ & $\begin{array}{l}\text { TGG } \\
\mathrm{W}\end{array}$ & $\mathrm{CCC}$ & TG & $\begin{array}{l}\text { AAT } \\
\mathrm{N}\end{array}$ & $\begin{array}{l}\text { GAG } \\
\mathrm{E}\end{array}$ & $\mathrm{CC}$ & CAG & $\begin{array}{l}\text { GTG } \\
\mathrm{V}\end{array}$ & CAG & GCC & $\begin{array}{l}\text { TCA } \\
\mathrm{S}\end{array}$ & $\begin{array}{l}\text { GTG } \\
\text { V }\end{array}$ & GTG & 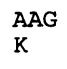 & \\
\hline & TC & TG & $\begin{array}{l}\mathrm{ACT} \\
\mathrm{T}\end{array}$ & $\begin{array}{l}\text { GAG } \\
\mathrm{E}\end{array}$ & $\begin{array}{l}\text { CTG } \\
\text { L }\end{array}$ & TG & $\begin{array}{l}\text { GAA } \\
\mathrm{E}\end{array}$ & $\begin{array}{l}\text { CAG } \\
Q\end{array}$ & $\begin{array}{l}\text { GAA } \\
\mathrm{E}\end{array}$ & $\begin{array}{l}\text { AGA } \\
\mathrm{R}\end{array}$ & $\begin{array}{l}\text { AAG } \\
\mathrm{K}\end{array}$ & AG & $\begin{array}{l}\text { GTG } \\
\text { V }\end{array}$ & $\begin{array}{l}\text { GTG } \\
\text { V }\end{array}$ & $\begin{array}{l}\text { GAC } \\
D\end{array}$ & $\begin{array}{l}\text { ACC } \\
\mathrm{T}\end{array}$ & $\begin{array}{l}\text { ACC } \\
T\end{array}$ & $\begin{array}{l}\text { AAG } \\
\mathrm{K}\end{array}$ & $\begin{array}{l}\text { GAG } \\
\mathrm{E}\end{array}$ & AGC & \\
\hline & GC & $\begin{array}{l}\text { AGG } \\
\mathrm{R}\end{array}$ & $\begin{array}{l}\text { AAG } \\
\mathrm{K}\end{array}$ & $\begin{array}{l}\text { GGC } \\
\text { G }\end{array}$ & $\begin{array}{l}\text { TGG } \\
\mathrm{W}\end{array}$ & AG & AGC & CGC & AG & $\begin{array}{l}\text { CGG } \\
R\end{array}$ & AAG & TA & TCG & GGA & GAC & CAG & $\begin{array}{l}\mathrm{CCA} \\
\mathrm{P}\end{array}$ & GCT & GCC & $\begin{array}{l}A G \\
R\end{array}$ & \\
\hline & $\mathrm{CC}$ & $\begin{array}{l}\mathrm{CCC} \\
\mathrm{p}\end{array}$ & $\begin{array}{l}\text { AGG } \\
\mathrm{R}\end{array}$ & $\begin{array}{l}\text { AGC } \\
S\end{array}$ & $\begin{array}{l}\text { AAG } \\
\mathrm{K}\end{array}$ & AG & $\begin{array}{l}\text { AAG } \\
\mathrm{K}\end{array}$ & $\begin{array}{l}\text { AAG } \\
\mathrm{K}\end{array}$ & & $\begin{array}{l}\text { CTG } \\
\text { L }\end{array}$ & $\begin{array}{l}\text { GGG } \\
\text { G }\end{array}$ & $\begin{array}{l}\text { GCC } \\
\text { A }\end{array}$ & $\begin{array}{l}\text { GGG } \\
\text { G }\end{array}$ & $\begin{array}{l}\text { GAA } \\
\mathrm{E}\end{array}$ & $\begin{array}{l}\text { GGT } \\
\text { G }\end{array}$ & $\begin{array}{l}\text { GGG } \\
\text { G }\end{array}$ & $\begin{array}{l}\text { GAG } \\
\mathrm{E}\end{array}$ & $\begin{array}{l}\text { GCC } \\
\mathrm{A}\end{array}$ & $\begin{array}{l}\text { TCT } \\
S\end{array}$ & $\begin{array}{l}\text { GT } \\
\text { V }\end{array}$ & \\
\hline & $\mathrm{CC}$ & $\begin{array}{l}\mathrm{CCA} \\
\mathrm{P}\end{array}$ & $\begin{array}{l}\text { GAA } \\
\mathbf{E}\end{array}$ & $\begin{array}{l}\text { AAG } \\
\mathrm{K}\end{array}$ & $\begin{array}{l}A C C \\
T\end{array}$ & CC & $\begin{array}{l}\text { ACG } \\
T\end{array}$ & $\begin{array}{l}\mathrm{ACT} \\
\mathrm{T}\end{array}$ & CC & AAG & $\begin{array}{l}\text { GGG } \\
\text { G }\end{array}$ & $\mathrm{AA}$ & GCA & $\begin{array}{l}\text { AAG } \\
\mathrm{K}\end{array}$ & $\begin{array}{l}\text { AGA } \\
\mathrm{R}\end{array}$ & GAC & $\begin{array}{l}\text { AAA } \\
K\end{array}$ & $\begin{array}{l}\text { GCA } \\
\mathrm{A}\end{array}$ & AGT & 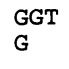 & \\
\hline & $\mathrm{AT}$ & $\begin{array}{l}\text { GTC } \\
\text { V }\end{array}$ & $\begin{array}{l}\text { AAG } \\
\mathrm{K}\end{array}$ & $\begin{array}{l}\text { GAG } \\
\mathrm{E}\end{array}$ & $\begin{array}{l}\text { AAG } \\
\mathrm{K}\end{array}$ & $\begin{array}{l}\text { AAA } \\
K\end{array}$ & $\begin{array}{l}\text { GGG } \\
\text { G }\end{array}$ & $\begin{array}{l}\text { AAG } \\
\mathrm{K}\end{array}$ & G & $T$ & $\begin{array}{l}\text { CTT } \\
\mathrm{L}\end{array}$ & GC & C & $\begin{array}{l}\mathrm{CAA} \\
\mathrm{Q}\end{array}$ & $\begin{array}{l}\text { GGG } \\
\text { G }\end{array}$ & $\begin{array}{l}\text { GCC } \\
\text { A }\end{array}$ & $\begin{array}{l}\text { AAG } \\
\mathrm{K}\end{array}$ & $\begin{array}{l}\text { GAC } \\
D\end{array}$ & $\begin{array}{l}\text { GAG } \\
\mathrm{E}\end{array}$ & 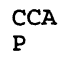 & \\
\hline $\begin{array}{l}1021 \\
1341\end{array}$ & AA & $\begin{array}{l}\text { GAG } \\
\text { E }\end{array}$ & $\begin{array}{l}\text { GAG } \\
\mathrm{E}\end{array}$ & $\begin{array}{l}\text { CTT } \\
\text { L }\end{array}$ & $\begin{array}{l}\text { CAG } \\
Q\end{array}$ & AG & $\begin{array}{l}\text { GGG } \\
\text { G }\end{array}$ & $\begin{array}{l}\text { ATG } \\
M\end{array}$ & GG & $\begin{array}{l}\text { ACG } \\
T\end{array}$ & $\begin{array}{l}\text { GTT } \\
\text { V }\end{array}$ & A & $\begin{array}{l}\text { GGT } \\
\text { G }\end{array}$ & $\begin{array}{l}\text { GGA } \\
\text { G }\end{array}$ & GAT & CAA & $\begin{array}{l}\text { AGC } \\
\mathrm{S}\end{array}$ & $\mathrm{AAC}$ & $\mathrm{CCA}$ & 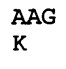 & \\
\hline & GC & $\begin{array}{l}\text { AAG } \\
\mathrm{K}\end{array}$ & $\begin{array}{l}\text { AAG } \\
\mathrm{K}\end{array}$ & $\begin{array}{l}\text { GAG } \\
\text { E }\end{array}$ & $\begin{array}{l}\text { AAG } \\
\mathrm{K}\end{array}$ & G & $\begin{array}{l}\text { AAA } \\
\mathrm{K}\end{array}$ & $\begin{array}{l}\text { TCC } \\
\mathrm{S}\end{array}$ & c & 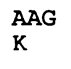 & $\begin{array}{l}\text { AGA } \\
\mathrm{R}\end{array}$ & A & $\begin{array}{l}\mathrm{AAA} \\
\mathrm{K}\end{array}$ & $\begin{array}{l}\text { GAC } \\
\text { D }\end{array}$ & $\begin{array}{l}\text { AAA } \\
K\end{array}$ & $\begin{array}{l}\text { GAA } \\
\mathrm{E}\end{array}$ & $\begin{array}{l}\mathrm{AAA} \\
\mathrm{K}\end{array}$ & $\begin{array}{l}\text { AAA } \\
K\end{array}$ & $\begin{array}{l}\text { GAA } \\
\mathrm{E}\end{array}$ & $\begin{array}{l}A A \\
K\end{array}$ & \\
\hline & AG & $\begin{array}{l}\text { AAG } \\
\mathrm{K}\end{array}$ & $\begin{array}{l}\text { AAA } \\
\mathrm{K}\end{array}$ & $\begin{array}{l}\text { GCA } \\
A\end{array}$ & $\begin{array}{l}\mathrm{AAA} \\
\mathrm{K}\end{array}$ & $\begin{array}{l}\text { AAG } \\
\mathrm{K}\end{array}$ & $\begin{array}{l}\text { GCC } \\
\text { A }\end{array}$ & $\begin{array}{l}\mathrm{TCA} \\
\mathrm{S}\end{array}$ & $\begin{array}{l}\mathrm{ACC} \\
\mathrm{T}\end{array}$ & $\begin{array}{l}\text { AAA } \\
\mathrm{K}\end{array}$ & $\begin{array}{l}\text { GAT } \\
\text { D }\end{array}$ & $\begin{array}{l}\mathrm{TCT} \\
\mathrm{S}\end{array}$ & $\begin{array}{l}\text { GAG } \\
\mathrm{E}\end{array}$ & $\begin{array}{l}\text { TCA } \\
\mathrm{S}\end{array}$ & $\begin{array}{l}\text { CCG } \\
\mathrm{P}\end{array}$ & $\begin{array}{l}\text { TCC } \\
\mathrm{S}\end{array}$ & $\begin{array}{l}\text { CAG } \\
Q\end{array}$ & $\begin{array}{l}\mathbf{A A G} \\
\mathbf{K}\end{array}$ & $\begin{array}{l}\mathrm{AAA} \\
\mathrm{K}\end{array}$ & 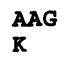 & \\
\hline 2 & AG & AAA & $\begin{array}{l}\mathbf{A A G} \\
\mathbf{X}\end{array}$ & $\begin{array}{l}\mathbf{A A G} \\
\mathbf{K}\end{array}$ & $\begin{array}{l}\mathbf{A A G} \\
\mathbf{K}\end{array}$ & $\begin{array}{l}\mathbf{A C A} \\
\mathbf{T}\end{array}$ & GCA & GA & CAG & $\begin{array}{l}\mathbf{A C T} \\
\mathrm{T}\end{array}$ & $\begin{array}{l}\text { GT } \\
\mathrm{v}\end{array}$ & . & & & & & & & & & \\
\hline $\begin{array}{l}4317 \\
4396 \\
4475\end{array}$ & st & 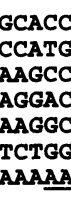 & s & AAGAC & c. & & $G$ & & & & & & AA & & & & & & & & $\begin{array}{l}395 \\
474 \\
553 \\
632 \\
711 \\
760\end{array}$ \\
\hline
\end{tabular}

Figure 1 Complete nucleotide sequence of TCOF1 (U40847) and the derived amino acid sequence of the protein Treacle. Position 1 is taken as the first base of the initiation codon. The single polyadenylation signal is underlined. The new sequence data (nucleotide and amino acid) are in boldface type. 
DIXON ET AL.

Table 1. Genomic Organization of the TCOF1 Locus

\begin{tabular}{|c|c|c|c|c|c|}
\hline Exon & $\begin{array}{l}\text { Size } \\
\text { (bp) }\end{array}$ & Splice Donor & Splice Acceptor & $\begin{array}{l}\text { Nucleotide } \\
\text { Position }\end{array}$ & $\begin{array}{l}\text { Intron } \\
\text { Size }\end{array}$ \\
\hline 1 & - & AGC GGC CAG gtaagcgttc & ctctctgcag AAG TGT TTC & $5^{\prime}$ UTR - 108 & - \\
\hline 2 & 56 & TGG CAA CA gtaagtggtg & tgtcctgcag A ACC TCA & $109-164$ & $2.7 \mathrm{~kb} \quad(P)$ \\
\hline 3 & 140 & gtaagagcct & tttcttgcag CC CCA AGA & $165-304$ & - \\
\hline 4 & 74 & AAA GCC AAG gtgagtggga & ttctctgtag GCA GAG ACA & $305-378$ & $860 \mathrm{bp} \quad(\mathrm{P})$ \\
\hline 5 & 187 & AAG CCT G gtaagaagtc & cgatcctcag GG ATG GTG & $379-565$ & $600 \mathrm{bp} \quad(\mathrm{P})$ \\
\hline 6 & 74 & GAC GTG GAG gtaattgcca & ttttcaccag GTA AAG GCC & $566-639$ & - \\
\hline 7 & 213 & CTG CTT CAG gtgaggcetg & gtttctccag GCG AAG GCC & $640-852$ & $230 \mathrm{bp} \quad(S)$ \\
\hline 8 & 195 & CCT GCT CAG gtgaggcaga & ctcactccag GCG AAG CCT & $853-1047$ & $142 \mathrm{bp} \quad(S)$ \\
\hline 9 & 210 & GCA GCT CAG gtgaggctgg & tgtctcccag GTG AAG CCC & $1048-1257$ & $175 \mathrm{bp} \quad(S)$ \\
\hline 10 & 216 & CCG GCT CAG gtgaggeccC & ctcactccag GAA AAG TCC & $1258-1473$ & $166 \mathrm{bp} \quad(S)$ \\
\hline 11 & 189 & GCA GCT CAG gtgaggcctg & gtccectcag GCA AAA CCA & $1474-1662$ & $171 \mathrm{bp}(S)$ \\
\hline 12 & 249 & GTG GGA CAG gtgaggcctg & gtcatcccag GCA AAG TCT & $1663-1911$ & $93 \mathrm{bp} \quad(\mathrm{S})$ \\
\hline 13 & 198 & CCA GCA CAG gtgaggccta & ctccactcag GTG AAA ACC & $1912-2109$ & - \\
\hline 14 & 138 & CCA TCC AAG gcaagtgggg & tgcaattcag GTG AAG CCA & $2110-2247$ & $185 \mathrm{bp}(S)$ \\
\hline 15 & 180 & CTG GCT CAG gtgaggggga & ctccctccag GCG AAG CCT & $2248-2427$ & $118 \mathrm{bp} \quad(S)$ \\
\hline 16 & 201 & TCT GCC CAG gtaagacttg & gttttccaag GTG ATT AAA & $2428-2628$ & - \\
\hline 17 & 187 & ACT CCT G gtgagcgacc & tccattccag GC ATC AGA & $2629-2815$ & $2 \mathrm{~kb} \quad(\mathrm{P})$ \\
\hline 18 & 137 & GCC ACT CAG gtacctggtg & ccacccacag GTG TCA AAG & $2816-2952$ & $1.6 \mathrm{~kb} \quad(P)$ \\
\hline 19 & 114 & TCA AGT GGG gtgagcttcC & accgaattag GTT GAC AGT & $2953-3066$ & $298 \mathrm{bp} \quad(S)$ \\
\hline 20 & 220 & ACG CTG G gtgagggtgc & tctccagtag GT CCC ACC & $3067-3286$ & $540 \mathrm{bp} \quad(\mathrm{P})$ \\
\hline 21 & 83 & CCA TCC CAG gtaactgcaa & gcttcttcag TCT CTC CTC & $3287-3369$ & $570 \mathrm{bp} \quad(\mathrm{P})$ \\
\hline 22 & 181 & gtaagttaag & ctctccatag GT GGA AAA & $3370-3550$ & $2.5 \mathrm{~kb} \quad(\mathrm{P})$ \\
\hline 23 & 561 & GAC AAG A gtgagtgacc & cttcccttag GA AAA AAA & $3551-4111$ & $1.6 \mathrm{~kb} \quad(\mathrm{P})$ \\
\hline 24 & 98 & AAG AAA AAG gtagagagtt & ctcctcacag AAG AAG ACA & $4112-4209$ & $570 \mathrm{bp} \quad(\mathrm{S})$ \\
\hline 25 & 49 & gtacgcttcc & cttccectag & $4210-4258$ & $730 \mathrm{bp} \mathrm{(P)}$ \\
\hline 26 & & \multicolumn{2}{|c|}{ 3' untranslated region } & $4259-4740$ & \\
\hline
\end{tabular}

The cDNA position of the intron/exon boundaries is defined relative to the sequence presented in this study with position 1 being the first base of the initiation codon. The intronic sequence is indicated in lowercase; the exonic sequence in uppercase. The codon usage is also indicated. The intron sizes were either determined by sequencing $(S)$ or by PCR analysis $(P)$. The genomic sequence information has been submitted to GenBank under accession nos. U79645-U79660, inclusive.

shown to map onto an individual exon. With the exception of exon 14, the repeated units extended from exon 7 to 16. In this region all of the intron/ exon boundaries are of type 0 and the splice donor sites are all of the consensus sequence /gtgagg, with the exception of the atypical intron 14 (Table 1).
Moreover, all of the introns in this region, with the exception of intron 13 , which precedes the atypical exon 14, have been sequenced and shown to be small, ranging in size from 93 to $230 \mathrm{bp}$ (Table 1). The repeat units were multiply aligned and shown to be highly conserved (Fig. 2). Exons 7, 8, 9, 10, 13, 
8 - AKASGKTSQV GAASAPAKES PRKGAAPA. . . PPGKTGP AVAKAQ... . AGKREEDS QSSSEE.SD. SEEEA. ... PAQ

9 - AKPSGKAPQV RAASAPAKES PRKGAAPA.. . . PPRKTGP AAAQVQ.... . . VGKQEEDS RSSSEE.SD. SDREALAAMN AAQ

16 - AKPSGKTHQI RAALAPAKES PRKGAAPT. . . . PPGKTGP SAAQAG.... . . . KQ.DDS GSSSEE.SD. SDGEAPAAVT SAQ

7 - VKASEKILQV RAASAPAKGT PGKGATPA.. . . . PPGKAGA VASQTK.... . . AGKPEEDS ESSSEESSD. SEEETPAAKA LLQ

10 - VKPLGKSPQV KPASTMGMGP LGKGAGPV. .... PPGKVGP ATPSAO...... VGKWEEDS ESSSEESSDS SDGEVPTAVA PAO

13 - AKSVGKGLQV KAASVPVKGS LGQGTAPV.. . . . LPGKTGP TVTQVK... . . AEK. QEDS ESSEEESDSE EAAAS... . PAQ

11 - EKSLGNILQA KPTSSPAKG. . . . . . . . . PPQKAGP VAVQVK....... . AEKPMDNS ESSEESSDSA DSEEAPAAMT AAQ

15 - VKPPVRNPQN STVLARG. . . . . PASVP. . . . SVGKAVA TAAQAQ . . . . . TG. PEEDS GSSEEESDSE EEAET. . . . LAQ

12 - AKPALKIPQT KACPKKTNTT ASAKVAPVRV GTQPPRKAGT ATSPAGSSPA VAGGTQRPAE DSSSSEESDS EEEKTGLAVT VGQ

Figure 2 Alignment of the most closely related repeated units identified within Treacle. The exon onto which each motif maps is indicated at left; the area of multiple potential sites for CKII phosphorylation is in boldface type.

and 16 were particularly homologous, with the most closely related being exons 8 and $16(77.41 \%$ identity, $87.10 \%$ similarity) and the least closely related being exons 7 and 13 (50\% identity, 59.09\% similarity) (Fig. 2). The protein sequence was also compared against pattern databases in an attempt to identify functional motifs within the sequence. These comparisons resulted in the identification of multiple motifs for casein kinase II phosphorylation (CKII) and protein kinase $\mathrm{C}$ phosphorylation. However, as these elements tend to be overpredicted by the programs, their significance is uncertain. It is, however, striking that multiple sites for CKII phosphorylation were observed in an identical position within each repeated unit (Fig. 2). Weak similarity to Xenopus laevis nucleolar phosphoprotein (S57757; $P=4.2^{\mathrm{e}-9}$ ) (Cairns and McStay 1995) and nucleolar phosphoprotein 140 (M94288; $P=2.6^{\mathrm{e}-8}$ ) (Meier and Blobel 1992) were demonstrated using the BLAST programs (Altschul et al. 1990). These highly phosphorylated proteins have a role in protein transport between the cytoplasm and the nucleus (Meier and Blobel 1992). Alignment of Treacle with these proteins indicated that this was predominantly a result of homology in the regions of the CKII sites within the repeated units of Treacle (Fig. 3). As is the case for the nucleolar phosphoproteins, the CKII phosphorylation sites occur within clusters of acidic amino acids, which are separated by stretches of residues that are relatively rich in lysine, proline, and alanine, with few acidic residues and are, therefore, basic in nature (Fig. 2). In addition, both Treacle and the nucleolar phosphoproteins display a number of motifs of the type K-K/R$\mathrm{X}-\mathrm{R} / \mathrm{K}$, which represents the minimal nuclear localization signal consensus sequence, toward the $3^{\prime}$ end of the coding sequence.

\section{DISCUSSION}

In this study we report the entire coding sequence of the TCOF1 gene and its genomic organization. The gene has an ORF of 4233 bp encoded by 25 exons. Exons 4, 5, 6, 15, 18, and 25 have also been recovered by exon amplification strategies (Treacher Collins Syndrome Collaborative Group 1996; Gladwin et al. 1996; this study). All of the splice junctions of the gene conform to the published consensus sequences (Breathnach and Chambon 1981), with the exception of the splice donor site of exon 14 , which has GC in place of the expected GT. A number of other genes exhibiting this unusual variation have been published, including the fibrillin gene (Pereira et al. 1993). Although the significance underlying this splice variant is unclear, it seems to be prone to mis-splicing events resulting from apparently minor nucleotide changes in the extended splice consensus sequence (Gladwin et al. 1996). A second unusual variation in the genomic organization of the gene has been observed in the current study in that the 3' UTR of TCOF 1 is not single exonic as has been reported for the vast majority of genes (Wilcox et al. 1991). Exceptions to this rule include the $\mathrm{p} 58^{\mathrm{clk}-1}$ protein kinase gene (Eipers et al. 1992) and the genes encoding the $\beta 1$ subunit of the voltage-dependent sodium channel in mouse, rat, and human (Dib-Hajj and Waxman 1995). These genes do not, however, appear to be related. The presence of the intron in the $3^{\prime}$ UTR is validated by the fact that exon 25 was successfully "rescued" by exon amplification using the pSPL3 vector system, which does not rescue the 3 ' terminal exon. The sequence and splicing of the exonamplified product corresponds exactly to the sequence of exon 25 .

The nucleotide sequence of TCOF 1 predicts a protein, Treacle, of 1411 amino acids, that is relatively rich in alanine and serine residues. Although Treacle does not exhibit strong homology to any known proteins, the use of a number of bioinformatics tools has highlighted several interesting features of the gene. There is a series of repeated units of unknown function within the gene that map onto individual exons. The splicing phase of all of the exons in this region is the same (type- 0 junctions); therefore, it is possible that this region of the 


\section{DIXON EI AL.}

gene has arisen by exon duplication during evolution. The gene also appears to be rich in potential phosphorylation sites, a number of which map to a similar position within the repeated units. However, as these motifs tend to be overpredicted by the programs, their significance remains unclear. In this regard cloning of the homolog of TCOF1 in other species will help to identify conserved and, hence, potentially functionally important, domains. Nevertheless, Treacle shows weak but significant homology to a small number of phosphorylated proteins, the nucleolar phosphoproteins. Alignments have indicated further that these homologies are detected most strongly in the regions of the CKII sites that exist within the repeated region of Treacle. Although the homology between Treacle and the nucleolar phosphoproteins is weak, the proteins do have several features in common. In all cases, alanine, serine, lysine, glutamic acid, and proline make up the majority of the amino acids. These low complexity proteins do, however, contain repeating units that consist of sites for CKII phosphorylation, which are embedded in clusters of acidic amino acids separated by stretches of basic residues. In the case of Treacle, we have identified 10 repeat units, although 1 appears to be atypical. Interestingly, rat nucleolar phosphoprotein and its human homolog also contain 10 repeats (Meier and Blobel 1992; Pai et al. 1995), although the Xenopus homolog contains 17 (Cairns and McStay 1995). In the case of TCOF1, these repeating units map onto individual exons; however, the genomic organization of the nucleolar phosphoproteins has not been determined, to our knowledge. Finally, all of the proteins possess nuclear localization signals toward their carboxyl termini. Although the precise role of the nucleolar phosphoproteins has not been elucidated, they have been shown to shuttle along curvilinear tracks from the nucleolus to the cytoplasm and have, as such, been implicated as a chaperone in nucleolar-cytoplasmic transport. In this regard, it has been suggested that the alternating acidic and basic domains could function to cover and neutralize highly charged domains of preribosomal particles
170 VSETEEEGSVPAFGAAAKPGMVSAGQADSSSEDTSSSSDETDVEVKASE . 218 $\therefore:|:||. \quad:|:|\ldots| \ldots \ldots . \ldots|\ldots| \ldots||$.

268 MADTGLRRVVPSDLYPLVLGFLRDNQLSEVASKFAKATGATQQDANASSL 317

219 .KILQVRAASAPAKGTPGKGATPAPPGKAGAVASQTKAGKPEEDSESSSE 267 |. ${ }_{1}||.|\ldots| \ldots: .|:| .|\ldots|||$

318 LDIYSFWLKS.......... TKAPKVKLQSNGPVAKKAKKETSSSDSSE 356

268 ESSDSEEETPAAKALLQAKASGKTSQVGAASAPAKESPRKGAAPAPPGKT 317 $:||:|: . \quad| \ldots \ldots|:||| \ldots:$.

357 DSSEEEDK. . . . . . . . . . . AQVPTQKAAAPAKRASL 381

318 GPAVAKAQAGKREEDSOSSSEESDSEEEAPAQAKPSGKAPQVRAASAPAK 367 $\ldots .|| \cdot|\quad \ldots:||| \cdot||:.|||+|.|\cdot||\ldots|$

382 PQHAGKAAA. . KASESSSSEESSEEEEEKDKKKKPVQKAVKPQAK . . . . 424

368 ESPRKGAAPAPPRKTGPAAAQVQVGKQEEDSRSSSEESDSDREALAAMNA 417 $425 \ldots$ | $\ldots:||: \mid \ldots:$ AVRPPRKAE $\ldots \ldots|||\ldots| . \mid$ |

$425 \ldots \ldots$. AVRPPPKKAE . . . . . . . . . SSESESDSSSEDEAP. . 449

418 AQVKPLGKSPQVKPASTMGMGPL. GKGAGPVPPGKVGPATPSAQVGKWEE 466 $450 \ldots \ldots$ QTQKPKAAATAAKAPTKAQTKAPAKPGPPAKAQPKAANGKAGS 492

467 DSESSSEESSDSSDGEVPTAVAPAQEKSLGNILQAKPTSSPAKGPPQKAG 516 . . . ||..|| |. : : : $|: \ldots| .:|$.$| ...$

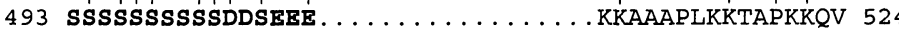

517 PVAVQVKAEKPMDNSESSEESSDSADSEEAPAAMTAAQAKPALKIPQTKA 566

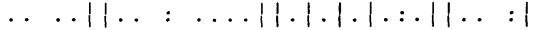
..

525 VAKAPVKVTAAPTOKSSSSEDSSSEEEEEOKKPM.......KKKA 562

567 CPKKTNTTASAKVAPVRVGTQPPRKAGTATSPAGSSPAVAGGTQRPAEDS 616 . | ...: ..... . ||.|.|:||: . | ||:||:

563 GPYSSVPPPSVSLSKKSVGAOSPKKAAAOTOPADSSA.......... DS 601

617 SSSEESDSEEEKTGLAVTVGQAKSVGKGLQVKAASVPVKGSLGQGTAPVL 666 |..: $\mid$. || || . | | |.

602 SEESDSSSEEEKKTPAKTVV . . . . . . . . . . . . 621

667 PGKTGPTVTQVKAEKQEDSESSEEESDSEEAAASPAQVKTSVKKTQAKAN 716 $:|| \ldots: \ldots|| . \quad \ldots|:||: \ldots:| \ldots:||:|$.$| .$

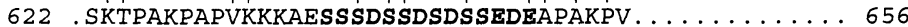

717 PAAARAPSAKGTISAPGKVVTAAAQAKQRSPSKVKPPVRNPQNSTVLARG 766

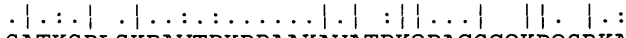

657 .SATKSPLSKPAVTPKPPAAKAVATPKQPAGSGQKPQSRKA . . . . . 696

767 PASVPSVGKAVATAAQAQTGPEEDSGSSEEESDSEEEAETLAQAKPSGKT 816

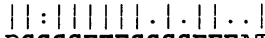

$697 \ldots \ldots \ldots \ldots \ldots \ldots \ldots \ldots$. . . . . . . . . . 713

817 HQIRAALAPAKESPRKGAAPTPPGKTGPSAAQAGKQDDSGSSSEESDSDG 866 $: \ldots: \mid \ldots$ | || |. |:| :|.|: $:||:||.|.| . \mid::$

$714 \ldots$ KKSVTTPKARVTAKAAPSLPAKQAPRAG. . . . GDSSSDSESSSSEE 755

867 EAPAAVTSAQVIKPPLIFVDPNRSPAGPAATPAQAQAASTPRKARASEST 916

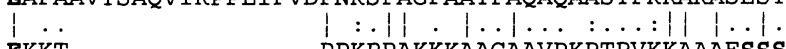

756 EKKT .......... PPKPPAKKKAAGAAVPKPTPVKKAAAESSS 789

917 ARSSSSESEDEDVIPATQCLTPGIRTNVVTMPTAHPRIAPKASMAGASSS 966

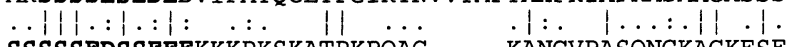
790 SSSSSEDSSEEEKKKPKSKATPKPQÄ . . . KANGVPASQNGKAGKESE 834

967 KESSRISDGKKQEGPATQVSKKNPASLPLTQAALKVIAQKASEAQPPVAR 1016

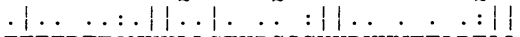

835 EEEEDTEQNKKAAGTKPGSGKKRKHNETADEAA. . . . . . . 867

1017 TQPSSGVDSAVGTLPATSPQSTSVQAKGTNKLRKPKLPEVQQATKAPESS 1066 $868 \ldots \ldots \ldots \ldots$ TPQSKKVKLQTPNTFPKRK $\ldots \ldots \ldots \ldots$ K 887

1067 DDSEDSSDSSSGSEEDGEGPQGAKSAHTLGPTPSRTETLVEETAAESSED 1116 $: \ldots . \mid$ |...||:| |:..|:.

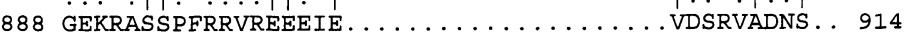

1117 DVVAPSQSLLSGYMTPGLTPANSQASKATPKLDSSPSVSSTLAAKDDPDG 1166 $: . \mid \quad::$

915 FDAKRGAAG 923

1167 KQEAKPQQAAGMLSPKTGGKEAASGTTPQKSRKPKKGAGNPQASTLALQSN 1217 :.:.|. : | | . : . . . . : . . . . : : : : 924 DWGERANQVLKF . . . TKGKSFRHEKTKKKRGSYRGGS ISVQVNSVKFDSE 970

Figure 3 (See facing page for legend.) 
(export) or ribosomal proteins (import) (Meier and Blobel 1992). The role of phosphorylation may be to increase the net negative charge in the acidic domain, thus increasing the affinity of the protein for oppositely charged species such as basic ribosomal proteins (Cairns and McStay 1995). Interestingly, recent data suggest that the complex events of epithelial-mesenchymal transformation in the neural crest cell system can be triggered by epigenetic events involving differential protein phosphorylation (Newgreen and Minichiello 1995). Nevertheless, although these interesting similarities provide potential insight into the function of the protein, additional experiments are required to confirm its role during facial development.

On the basis of the TCS phenotype, the gene must play a fundamental role in early embryonic development, possibly via an effect on neural crest cell migration and/or differentiation (Poswillo 1975; Wiley et al. 1983). In this regard, determination of the precise spatiotemporal expression patterns of the gene, and its protein product Treacle during development will be important in the investigation of the function of the gene. Here, the use of animal models, where accurately staged embryos from a wide variety of developmental stages are readily obtainable, will be extremely valuable. Furthermore, the isolation of the complete coding sequence of TCOF1 and the determination of its genomic organization reported here will prove to be helpful in the isolation and characterization of its murine homolog, which is essential in the creation of a mouse model of TCS by gene targeting.

As the vast majority of the mutations that have been reported in TCOF1 to date are unique to the family in which they were identified and are spread throughout the gene (Gladwin et al. 1996; Treacher Collins Syndrome Collaborative Group 1996; M.J. Dixon and S.J. Edwards, unpubl.), elucidation of the complete genomic organization of the gene will facilitate continued mutation screening, which may provide further information on functionally important domains within the gene and confirm the hypothesis that TCS results from haploinsufficiency. With the exception of exon 23 of TCOF1, all of the exons are $<250 \mathrm{bp}$ in size and are therefore of an appropriate size to be analyzed as a single fragment by single-stranded conformation polymorphism
(SSCP) analysis (Orita et al. 1989). Although this technique is not sufficiently sensitive to identify all potential mutations, it does provide an excellent balance between simplicity and sensitivity of detection. In addition to providing information on the mutational spectrum underlying TCS, continued mutation analysis will also prove to be important for postnatal diagnosis of TCS, particularly in cases where there is some doubt as to diagnosis of either parent of a child with obvious clinical signs of TCS. Molecular diagnosis will also be important in providing prenatal diagnostic predictions for "at-risk" families (Edwards et al. 1996) and in assessing whether patients with conditions in which the facial gestalt has some similarities to the TCS facies, such as Nager and Miller syndrome (Gorlin et al. 1990), are also attributable to mutations in TCOF1.

\section{METHODS}

\section{$5^{\prime}$ and $3^{\prime}$ RACE}

First-strand cDNA synthesis was performed on $500 \mathrm{ng}$ of poly $(\mathrm{A})^{+}$RNA isolated from skeletal muscle (Clontech) and a lymphoblastoid cell line using the $5^{\prime}$ or $3^{\prime}$ RACE kit (BRL) according to the manufacturer's instructions. In the case of $5^{\prime}$ RACE, CDNA synthesis was initiated from the gene-specific primer 5'-TTCCCAGTCTTGCCAG-3'. The original mRNA template was then removed by treatment with RNase $\mathrm{H}$. In the case of $5^{\prime}$ RACE products, a homopolymeric tail was added to the 3 ' end of the cDNA using terminal deoxynucleotide transferase (Tdt) and dCTP. PCR amplification of the target cDNA was performed using the universal amplification primer and a $5^{\prime}$ RACE gene-specific primer, 5' TTTCGGCTTCTGCTTCTTCC-3', or a 3' RACE gene-specific primer, 5'-GGCCTCAACCAAAGATTC-3'. After electrophoretic separation on a $1 \%$ agarose gel, the PCR product was diluted and subject to a second round of PCR using the abridged universal amplification primer and a nested 5' RACE gene-specific primer, 5'-CTGAATTCAGATGTCCAGAAGGGTTACG-3' or a nested 3' RACE gene-specific primer, 5'AAGAATTCTGAGTCACCGTCCCAG-3'. The resulting PCR products were gel-purified, digested with EcoRI/SalI, cloned into M13mp18/19, and sequenced via the dideoxy chain termination method (Sanger et al. 1977) using the Sequenase version 2.0 kit (U.S. Biochemical Corp.).

\section{RT-PCR}

One microgram of RNA extracted from skeletal muscle or a lymphoblastoid cell line was incubated with $100 \mathrm{ng}$ of random primer at $70^{\circ} \mathrm{C}$ for $10 \mathrm{~min}$. The samples were chilled on ice, and Moloney murine leukemia virus (MMLV) reverse

Figure 3 Comparison of the predicted amino acid sequences of the human Treacle protein and the rat nucleolar phosphoprotein using BESTFIT alignment. The top line represents the single-letter amino acid sequence of human Treacle; and the bottom line is the rat nucleolar phosphoprotein sequence. The sequences display $32.43 \%$ identity and $46.86 \%$ similarity. The regions containing multiple potential sites for CKII phosphorylation are in boldface type. 


\section{DIXON ET AL.}

transcriptase buffer, $10 \mathrm{~mm}$ DTT, $1 \mathrm{~mm}$ dNTPs (all BRL), and 0.5 units of RNAsin (Promega) were added. The reactions were equilibrated at $37^{\circ} \mathrm{C}$ for $2 \mathrm{~min}, 100$ units of MMLV reverse transcriptase was added, and the samples incubated at $37^{\circ} \mathrm{C}$ for $1 \mathrm{hr}$. The samples were then heated to $95^{\circ} \mathrm{C}$ for $5 \mathrm{~min}$, and $3 \mu \mathrm{l}$ of cDNA was used in the PCR with the primers $5^{\prime}$. TTGGATCCAAGTGGGGCGCGCGAGGT-3' and 5'TCGAATTCTGGTAGATCAGGGGAAGTAG-3'. Control reactions included those performed in the absence of RNA or in the absence of reverse transcriptase.

\section{PCR Conditions}

PCR assays were performed in 25 - $\mu$ l volumes containing 50 pmoles of each primer; $200 \mu \mathrm{M}$ each of dCTP, dGTP, dTTP, and dATP; $10 \mathrm{~mm}$ Tris- $\mathrm{HCl}$ at $\mathrm{pH} 8.3,50 \mathrm{~mm} \mathrm{KCl}, 1.5 \mathrm{~mm}$ $\mathrm{MgCl}_{2}$, and $0.01 \%$ gelatin. The samples were overlaid with mineral oil, heated to $96^{\circ} \mathrm{C}$ for $10 \mathrm{~min}$ and cooled to $55^{\circ} \mathrm{C}$. After addition of 0.75 units of Taq DNA polymerase, the samples were processed through 35 amplification cycles of $92^{\circ} \mathrm{C}$ for $30 \mathrm{sec}, 55^{\circ} \mathrm{C}$ for $30 \mathrm{sec}$, and $72^{\circ} \mathrm{C}$ for $30 \mathrm{sec}$ using a Hybaid thermal cycler. The final extension step was lengthened to $10 \mathrm{~min}$. Positive and negative controls were established for all reactions. The PCR products were analyzed on $2 \%-3 \%$ agarose gels.

\section{Screening of cDNA Libraries}

Bacteriophage from muscle, placental (Stratagene Cloning Systems), and fetal brain (Clontech) cDNA libraries were plated at $5 \times 10^{4} \mathrm{PFU} / 140$-mm petri dish. Approximately $5 \times 10^{5}$ plaques were screened with restriction fragments of the original TCOF1 cDNA (Treacher Collins Syndrome Collaborative Group 1996) or RACE products using standard procedures. Positive primary clones were purified by two additional rounds of screening and subcloned into pBluescript. The resulting plasmids were restriction mapped, and suitable restriction fragments were subcloned into M13mp18/19 and sequenced.

\section{Exon Amplification}

Genomic DNA from cosmids $17-1$ and 18-3 were digested to completion with either PstI, or double-digested with BamHI and $B g l I I$. The restriction fragments were ligated into corresponding sites of the pSPL3 vector. The exon amplification protocol of Church et al. (1994) was followed with modifications reported previously (Treacher Collins Syndrome Collaborative Group 1996). Exon amplification clones were sequenced as above.

\section{Determination of Intron/Exon Boundaries}

Cosmids 17-1 and 18-3 were digested with Sau3A1, AluI, PstI, and SstI and shotgun-cloned into M13. Recombinant plaques were screened with restriction fragments of the TCOF1 cDNA or RACE products. Sequence data generated from the positive clones were compared with the cDNA sequence, and intronexon boundaries were identified by comparison with the published consensus sequences (Breathnach and Chambon 1981).

\section{Bioinformatics Analysis}

DNA and derived protein sequences were used to query the GenBank, NBRF, Swissprot, and TREMBL databases using the BLAST suite of programs; BLASTP was used to compare Treacle to the OWL protein database (Altschul et al. 1990; Bleasby et al. 1994). A dot plot of Treacle versus Treacle was created using the GCG programs COMPARE (window size, 30; stringency, 18) and DotPlot (Devereux et al. 1984). Multiple alignments of the repeated units of Treacle were produced using GCG PILEUP and edited using LINEUP. PROSITE, PRINTS, and BLOCKS databases were searched to identify protein motifs within Treacle (Bairoch 1991; Attwood et al. 1994; Henikoff and Henikoff 1994). The above programs were accessed using either SEQNET or the Human Genome Mapping Resource Centre (Hinxton, UK).

\section{ACKNOWLEDGMENTS}

The financial support of the Wellcome Trust [grants 044684/ Z/95/Z (M.J.D.) and 044327/Z/95/Z (M.J.D.)] and the Hearing Research Trust [grant 150:MAN:MD (M.J.D.)] is gratefully acknowledged. J.D. was supported, in part, by a HUGO travel award. This work benefitted from the use of the SEQNET and Human Genome Mapping Resource Centre computing facilities.

The publication costs of this article were defrayed in part by payment of page charges. This article must therefore be hereby marked "advertisement" in accordance with 18 USC section 1734 solely to indicate this fact.

\section{REFERENCES}

Altschul, S.F., W. Gish, W. Miller, E.W. Myer, and D.J. Lipman. 1990. Basic local alignment search tool. J. Mol. Biol. 215: 403-410.

Attwood, T.K., M.E. Beck, A.J. Bleasby, and D.J. Parry-Smith. 1994. PRINTS-A database of protein motif fingerprints. Nucleic Acids Res. 22: 3590-3586.

Bairoch, A. 1991. PROSITE: A dictionary of sites and patterns in proteins. Nucleic Acids Res. 19: 2241-2245.

Bleasby, A.J., D. Akrigg, and T.K. Attwood. 1994. OWL-A non-redundant composite protein sequence database. Nucleic Acids Res. 22: 3574-3577.

Breathnach, R. and P. Chambon. 1981. Organization and expression of eukaryotic split genes coding for proteins. Annu. Rev. Biochem. 50: 349-383.

Cairns, C. and B. McStay. 1995. Identification and cDNA cloning of a Xenopus nucleolar phosphoprotein, xNopp180, that is the homolog of the rat nucleolar protein Nopp140. J. Cell. Sci. 108: 3339-3347.

Church, D.M., C.J. Stotler, J.L. Rutter, J.R. Murrel, J.A. Trofatter, and A.J. Buckler. 1994. Isolation of genes from complex sources of mammalian genomic DNA using exon amplification. Nature Genet. 6: 98-105.

Devereux, J., P. Haeberli, and O. Smithies. 1984. A comprehensive set of sequence analysis programs for the VAX. Nucleic Acids Res. 12: 387-395. 


\section{CHARACIERIZATION OF ICOFI}

Dib-Hajj, S.D. and S.G. Waxman. 1995. Genes encoding the $\beta 1$ subunit of voltage-dependent $\mathrm{Na}^{+}$channel in rat, mouse and human contain conserved introns. FEBS Lett. 377: 485-488.

Dixon, M.J., A.P. Read, D. Donnai, A. Colley, J. Dixon, and R. Williamson. 1991. The gene for Treacher Collins syndrome maps to the long arm of chromosome 5. Am. J. Hum. Genet. 49: 17-22.

Dixon, M.J., J. Dixon, T. Houseal, M. Bhatt, D.C. Ward, K. Klinger, and G.M. Landes. 1993. Narrowing the position of the Treacher Collins syndrome locus to a small interval between three new microsatellite markers at 5q32-33.1. Am. J. Hum. Genet. 52: 907-914.

Dixon, M.J., H.A.M. Marres, S.J. Edwards, J. Dixon, and C.W.R.J. Cremers. 1994a. Treacher Collins syndrome: Correlation between clinical and genetic linkage studies. Clin. Dysmorphol. 3: 96-103.

Dixon, J., A.J. Gladwin, S.K. Loftus, J. Riley, R. Perveen, J.J. Wasmuth, R. Anand, and M.J. Dixon. 1994b. A yeast artificial chromosome contig encompassing the Treacher Collins syndrome critical region at 5q31.3-32. Am. J. Hum. Genet. 55: 372-378.

Edwards, S.J., A. Fowlie, M.P. Cust, D.T.Y Liu, I.D. Young, and M.J. Dixon. 1996. Prenatal diagnosis in Treacher Collins syndrome using combined linkage analysis and ultrasound imaging. J. Med. Genet. 33: 603-606.

Eipers, P.G., J.M. Lahti, and V.J. Kidd. 1992. Structure and expression of the human p58clk-1 protein kinase chromosomal gene. Genomics 13: 613-621.

Fazen, L.E., J. Elmore, and H.L. Nadler. 1967. Mandibulo-facial dysostosis (Treacher Collins syndrome). Am. J. Dis. Child. 113: 406-410.

Gladwin, A.J., J. Dixon, S.K. Loftus, S. Edwards, J.J. Wasmuth, R.C.M. Hennekam, and M.J. Dixon. 1996. Treacher Collins syndrome may result from insertions, deletions or splicing mutations, which introduce a termination codon into the gene. Hum. Mol. Genet. 5: $1533-1538$.

Gorlin, R.J., M.M. Cohen, and L.S. Levin. 1990. Syndromes of the head and neck. Oxford University Press, Oxford, UK.

Henikoff, S. and J.G. Henikoff. 1994. Protein family classification based on searching a database of blocks. Genomics 19: 97-107.

Jabs, E.W., X. Li, C.A. Coss, E.W. Taylor, D.A. Meyers, and J.L. Weber. 1991. Mapping the Treacher Collins syndrome locus to 5q31.3-q33.3. Genomics 11: 193-198.

Jabs, E.W., X. Li, M. Lovett, L.H. Yamaoka, E. Taylor, M.C. Speer, C. Coss, R. Cadle, B. Hall, K. Brown, K.K. Kidd, G. Dolganov, M.H. Polymeropoulos, and D. Meyers. 1993. Genetic and physical mapping of the Treacher Collins syndrome locus with respect to loci in the chromosome $5 \mathrm{q} 3$ region. Genomics 18: 7-13.
Jones, K.L., D.W. Smith, M.A. Harvey, B.D. Hall, and L. Quan. 1975. Older paternal age and fresh gene mutation: Data on additional disorders. J. Pediatr. 86: 84-88.

Kay, E.D. and C.N. Kay. 1989. Dysmorphogenesis of the mandible, zygoma and middle ear ossicles in hemifacial microsomia and mandibulofacial dysostosis. Am. J. Med. Genet. 32: 27-31.

Kozak, M. 1987a. An analysis of 5'-noncoding sequences from 699 vertebrate messenger RNAs. Nucleic Acids Res. 15: $8125-8148$.

1987b. At least six nucleotides preceding the AUG initiator codon enhance translation in mammalian cells. $J$. Mol. Biol. 196: 947-950.

Loftus, S.K., S.E. Edwards, T. Scherpbier-Heddema, K.H. Buetow, J.J. Wasmuth, and M.J. Dixon. 1993. A combined genetic and radiation hybrid map surrounding the Treacher Collins syndrome locus on chromosome 5q. Hum. Mol. Genet. 11: 1785-1792.

Loftus, S.K., J. Dixon, K. Koprivnikar, M.J. Dixon, and J.J. Wasmuth. 1996. Transcriptional map of the Treacher Collins candidate gene region. Genome Res. 6: 26-34.

Meier, U.T. and G. Blobel. 1992. Nopp140 shuttles on tracks between nucleolus and cytoplasm. Cell 70: 127-138.

Newgreen, D.F. and J. Minichiello. 1995. Control of epitheliomesenchymal transformation. Events in the onset of neural crest cell migration are separable and inducible by protein kinase inhibitors. Dev. Biol. 170: 91-101.

Orita, M., H. Iwahana, H. Kanazawa, K. Hayashi, and T. Sekiya. 1989. Detection of polymorphisms of human DNA by gel electrophoresis as single-strand conformation polymorphisms. Proc. Natl. Acad. Sci. 86: 2766-2770.

Pai, C.Y., H.K. Chen, H.L. Sheu, and N.H. Yeh. 1995. Cell cycle-dependent alterations of a highly phosphorylated nucleolar protein p130 are associated with nucleologenesis. J. Cell Sci. 108: 1911-1920.

Pereira, L., M. D'Alessio, F. Ramirez, J.R. Lynch, B. Sykes, T. Pangilinan, and J. Bonadio. 1993. Genomic organization of the sequence coding for fibrillin, the defective gene product in Marfan syndrome. Hum. Mol. Genet. 7: 961-968.

Phelps, P.D., D. Poswillo, and G.A.S. Lloyd. 1981. The ear deformities in mandibulofacial dysostosis (Treacher Collins syndrome). Clin. Otolaryngol. 6: 15-28.

Poswillo, D. 1975. The pathogenesis of Treacher Collins syndrome (mandibulofacial dysostosis). Br. J. Oral Surg. 13: $1-26$.

Sanger, F., S. Nicklen, and A.R. Coulson. 1977. DNA sequencing with chain terminating inhibitors. Proc. Natl. Acad. Sci. 74: 5463-5467.

Thompson, A. 1846. Notice of several cases of malformation 


\section{DIXON ET AL.}

of the external ear, together with experiments on the state of hearing in such persons. Monthly J. Med. Sci. 7: 420.

Treacher Collins, E. 1900. Cases with symmetrical congenital notches in the outer part of each lid and defective development of the malar bones. Trans.

Ophthalmol. Soc. U.K. 20: 190-192.

Treacher Collins Syndrome Collaborative Group. 1996.

Positional cloning of a gene involved in the pathogenesis of Treacher Collins syndrome. Nature Genet. 12: 130-136.

Wilcox, A.S., A.S Khan, J.A. Hopkins, and J.M. Sikela. 1991. Use of $3^{\prime}$ untranslated sequences of human cDNAs for rapid chromosome assignment and conversion to STSs:

Implications for an expression map of the genome. Nucleic Acids Res. 19: 1837-1843.

Wiley, M.J., P. Cauwenbergs, and I.M. Taylor. 1983. Effects of retinoic acid on the development of the facial skeleton in hamsters: Early changes involving cranial neural crest cells. Acta Anat. 116: 180-192.

Received October 9, 1996; accepted in revised form January 9, 1997. 


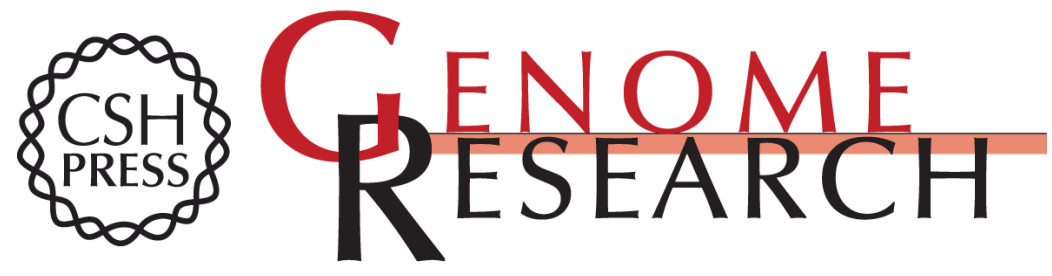

\section{Identification of the complete coding sequence and genomic organization of the Treacher Collins syndrome gene.}

J Dixon, S J Edwards, I Anderson, et al.

Genome Res. 1997 7: 223-234

Access the most recent version at doi:10.1101/gr.7.3.223

References This article cites 39 articles, 6 of which can be accessed free at:

http://genome.cshlp.org/content/7/3/223.full.html\#ref-list-1

\section{License}

Email Alerting Receive free email alerts when new articles cite this article - sign up in the box at the Service top right corner of the article or click here.

\section{Affordable, Accurate Sequencing.}

To subscribe to Genome Research go to:

https://genome.cshlp.org/subscriptions 